\title{
EFFICIENCY OF TREATMENT OF INFLAMMATORY PERIODONTAL DISEASES IN PREGNANT WOMEN
}

DOI: 10.36740/WLek202105103

\author{
Nataliia G. Gadzhula, Olena L. Cherepakha, Olena V. Lezhnova \\ NATIONAL PIROGOV MEMORIAL MEDICAL UNIVERSITY, VINNYTSIA, UKRAINE
}

\begin{abstract}
The aim: To study the clinical efficciency of the proposed scheme of gingivitis treatment in women with physiological course of pregnancy.

Materials and methods: Clinical approbation of the proposed complex of therapeutic and prophylactic measures was carried out in 32 pregnant women with gingivitis, aged 18 to 35 years. The efficiency of the treatment was assessed by the dynamics of the clinical picture, the index assessment of an oral hygiene and the periodontium condition in each trimester of pregnancy.

Results: According to the data of performed observations, the high efficiency of the proposed treatment scheme is shown: $84.4 \%$ in the main group versus $46.9 \%$ in the control group. It has been clinically proven that the proposed scheme of inflammatory periodontal diseases treatment in terms of therapeutic efficiency exceeds the generally accepted basic treatment.

Conclusions: The use of the proposed complex of therapeutic and prophylactic measures in the main group of patients contributed to the elimination of the inflammatory process in the periodontal tissues, suspended the progression of existing diseases, made it possible to prevent the emergence of new nosological forms, improved the condition of the oral hygiene, which makes it possible to recommend it for treatment of periodontal diseases in pregnant women.
\end{abstract}

KEY WORDS: pregnant women, gingivitis, gingival index, hyaluronic acid gel, probiotics

Wiad Lek. 2021;74(5):1065-1068

\section{INTRODUCTION}

In women during pregnancy, the periodontal status deteriorates, the prevalence increases and the structure of periodontal disease changes $[1,2]$. Various forms of gingivitis and generalized periodontitis occur, or the course of existing periodontal disease exacerbates $[3,4]$. These changes are due to temporary endocrine disharmony and neurohumoral shifts in a woman's body during pregnancy. As a result of the adjustment of the hormonal balance in women during pregnancy, the structure of the gums, the composition and properties of the mixed saliva change, and the reactivity of the organs and tissues of the oral cavity decreases [5, 6]. Clinical signs of gingivitis in pregnant women closely correlate with the level of estrogen, progesterone, placental gonadotropin in the blood during this period $[4,7]$. A certain role in the occurrence of pathological processes in the periodontal tissues is played by changes in the tone of the autonomic nervous system and vascular disorders that arise in conditions of impaired mineral and protein metabolism, endogenous hypovitaminosis and the parathyroid glands dysfunctions [6].

The key local factors in the development of gingivitis in pregnant women are an increase in the pathogenicity of microflora due to the enhanced proliferation of opportunistic microorganisms. The bacterial factor causes the breakdown of hyaluronic acid by the enzyme hyaluronidase, which leads to damage to the tissue structure, disruption of re- spiratory processes, increased capillary wall permeability, the development of tissue hypoxia, slowing down of cell proliferation and regeneration and, as a consequence, the progression of pathological processes in the periodontium $[1,8]$. Antibacterial agents used to treat periodontal diseases are quite strong dysbiotic factors that further contribute to the artificial reproduction of pathogenic bacteria with multiple resistance to them [9]. Therefore, in case of inflammatory processes in the periodontium, it is advisable to prescribe hyaluronic acid to improve the metabolism of non-sulfated glycosaminoglycans, and to restore the state of colonization resistance of the oral biofilm and prevent recurrence of diseases, the probiotic L. reuteri Prodentis.

\section{THE AIM}

The aim of the work was to study the clinical efficiency of the proposed scheme of gingivitis treatment in women with physiological pregnancy.

\section{MATERIALS AND METHODS}

The dental status of 136 women aged 18 to 35 years in each trimester of pregnancy was studied. The gestation period was divided into trimesters according to the generally accepted scheme: I trimester - 1-14 weeks, II trimester - 15-27 weeks, III trimester - 28-40 weeks. All 
women provided an informed consent, underwent a full dispensary examination and had a physiological course of pregnancy. During the clinical examination, the following were assessed: color, size, shape, consistency, surface texture, contour of the gingiva, the presence of edema and bleeding. The hygiene index was calculated according to G.C. Green, J.R. Vermillion (OHI-S, 1964). To assess the condition and degree of gingival inflammation, the Schiller-Pisarev's test was used with the determination of iodine number by Svrakov, the condition of the periodontal tissues was objectified based on the analysis of the Papillary-Marginal-Attachment Index (PMA) in the modification by C. Parma (1960) and the Papillary Bleeding Index (PBI) according to Muhlemann-Sax (1977). Diagnosis of diseases in pregnant women was carried out according to the classification of periodontal diseases by M.F. Danylevskyi (1994) with additions by G.F. Biloklytska (2007).

Statistical analysis of the study results was carried out using computer programs Microsoft Excel 2017 for Mac (corporate license, Product ID: 02984-001-000001; Device Code: 86C36D0C-8F15-59CA-A81E-B1D889205F71) and the licensed package "Statistica 6.1" (serial number BXXR901E246022FA). Statistical data processing was performed by methods of variation statistics with the calculation of average arithmetic and relative values and errors $(\mathrm{M} \pm \mathrm{m}),(\mathrm{P} \pm \mathrm{m})$, standard deviation $(\mathrm{t})$ and the significance of differences ( $\mathrm{p}$-value, the differences were considered statistically significant at $\mathrm{p}<0.05)$. In the case of confirmation of the normal distribution law when comparing quantitative indicators between groups, we used parametric methods - Student's t-test for independent variables, and to identify differences in dynamics during prophylactic and therapeutic measures, Student's t-test for dependent variables.

Among the examined women, 64 patients (47.06 \pm $6.24 \%$ ) with catarrhal inflammation of periodontal tissues were identified, who were diagnosed mainly with chronic catarrhal gingivitis. These women were evenly divided into 2 groups - the main and the control, 32 in each one. The sample was homogeneous, the groups did not include pregnant women with significant pathology of the maxillofacial region and severe somatic diseases. Pregnant women of both groups underwent a set of therapeutic and prophylactic measures, which included: professional oral hygiene, training in proper teeth brushing, forming a stable positive motivation for individual oral hygiene and monitoring its proper level, treatment of oral cavity diseases, correction of nutrition with obligatory approval by the nutritionist, healthy lifestyle, regular physical activity, taking into account the recommendations of the obstetrician-gynecologist, sanitary-educational work.

The application on the gums of Gengigel' Gingival Gel (Ricerfarma s.r.l., Italy), based on hyaluronic acid, for women of the main group were added to the treatment scheme for 14 days in each trimester of pregnancy: daily double application of the gel for 2-3 minutes by the method of finger massage of the gums of both jaws. In order to restore the state of colonization resistance of the oral biofilm and prevent recurrence of periodontal diseases, the probiotic L. reuteri Prodentis "BioGaia Prodentis" (BioGaia, Sweden) was prescribed, 1 lozenge sublingually for resorption, 20 days in each trimester of pregnancy after professional oral hygiene. In the control group of women, gingivitis was treated with traditional drugs (the affected areas of the gums were treated with conventional antiseptics) according to the protocols for the provision of dental care.

The studies were carried out in compliance with the main provisions of the "Rules of ethical principles for performing the scientific medical researches with human participation", approved by the declaration of Helsinki, ICH GCP, EEC Directive No.609, orders of the Ministry of Health of Ukraine No. 690 dated 23.09.2009, No. 944 dated 14.12.2009 y., No. 616 dated 03.08.2012. The study protocol was approved by the biomedical ethics committee of National Pirogov Memorial Medical University, Vinnytsya.

\section{RESULTS}

At the initial examination, the complaints of pregnant women in the two groups were identical: discomfort in the gums, itching, bad breath, bleeding gums while eating and brushing teeth. $18.75 \%(12 / 64)$ of women complained of spontaneous bleeding. During examination the diffuse hyperemia with pronounced cyanosis of the gingival margin, pronounced edema of the interdental gingival papillae, their friability and pastiness, pain on palpation were revealed. The average values of PBI was $1.92 \pm 0.11$, Svrakov's iodine number $-4.20 \pm 0.19$ scores. The values of PMA and OHI-S were quite high $(42.40 \pm 2.14 \%$ and $2.01 \pm 0.09$ scores), which indicated a moderate stage of gingivitis and low oral hygiene.

After the treatment in the first trimester of pregnancy, the women of the main group noted a significant improvement in the condition of the gums, the absence of pain and unpleasant odor, the disappearance of bleeding and swelling of the gums, and the pale pink color of the gingiva. There was a tendency towards a significant decrease $(\mathrm{p}<0.001)$ in the values of PMA (14.32 $\pm 1.24 \%)$, Svrakov's iodine number $(0.24 \pm 0.02$ scores), PBI $(0.32 \pm 0.08)$ and $\mathrm{OHI}-\mathrm{S}$ (0.98 \pm 0.08 scores).

The women of the control group, after the basic treatment, indicated a decrease in the pain and bleeding of the gums when eating and teeth brushing, and the absence of bad breath. An objective examination in $68.75 \%(22 / 32)$ of patients showed an improvement in the condition of the gums: the disappearance of gingival bleeding and swelling, a pale pink color of the gingiva. However, in $31.25 \%(10 / 32)$ of women in this group, there were signs of mild inflammation in the form of markedly pronounced hyperemia, edema and soreness, the presence of linear punctate bleeding. According to PMA index, the prevalence of low-intensity gingivitis $(24.60 \pm 1.44 \%, \mathrm{p}<0.001)$ was established, Svrakov's iodine number was $2.28 \pm 0.16$ scores. There was a decrease in the OHI-S to $1.42 \pm 0.09$ scores $(\mathrm{p}<0.001)$, which corresponds to a satisfactory level of oral hygiene. 
In the II-III trimesters of pregnancy, under the influence of local treatment, women in the main group noted a significant improvement in the appearance of the gums, the absence of pain, bleeding, and halitosis. As a result of the applied treatment scheme, inflammation in the gums significantly decreased, as indicated by a decrease (2.7 times) in the PMA index values: in the II trimester to $15.70 \pm 1.25 \%$, in the III - to $14.80 \pm 1.17 \%(p<0.001)$, respectively. The gingiva has acquired a pale pink color, the swelling of the gums has disappeared. The value of Svrakov's number and bleeding index were zero. Only $15.63 \%$ (5/32) of women in this group had signs of mild inflammation in the form of noticeably pronounced hyperemia, the presence of moderately pronounced edema of the gingival margin, a slight increase in the volume of the gingival papillae, and the presence of punctate bleeding during probing. The use of the proposed therapeutic and prophylactic complex in the main group of pregnant women contributed to a significant improvement in the hygienic condition of the oral cavity in the II and III periods of gestation. The values of OHI-S in the second trimester of pregnancy were $1.15 \pm 0.09$ scores, in the third - respectively, $1.11 \pm$ 0.08 scores and decreased on average by 2 times $(\mathrm{p}<0.001)$. Pregnant women did not notice any unpleasant sensations during the entire period of using gel and perceived the drug well due to its excellent sensory characteristics.

In the control group of women, chronic catarrhal gingivitis was registered in $37.50 \%(12 / 32)$ of cases, hypertrophic gingivitis - in $12.50 \%$ (4/32). Pregnant women with catarrhal type of inflammation complained of severe soreness of the gums, especially when teeth brushing and while eating, bleeding, and halitosis. Objective examination revealed edema, hyperemia of the gums with a cyanotic tinge, foci of epithelial desquamation, single erosion, and increased accumulation of dental plaque.

The complaints of women with a proliferative type of inflammation were about overgrowth of the gums, itching, minor bleeding and their soreness, which aggravated by eating. At examination the gingival mucosa is cyanotically hyperemic, pasty, the gingival papillae are enlarged to $1 / 3$ of the tooth crown height, which corresponds to the 1st degree. The PBI increased to $1.64 \pm 0.10(\mathrm{p}<0.001)$, the Svrakov's iodine number - to $4.36 \pm 0.21$ scores $(\mathrm{p}<0.001)$. The values of PMA and OHI-S are quite high (47.25 \pm $1.79 \%$ and $2.46 \pm 0.04$ scores, $\mathrm{p}<0.001$ ), which objectively indicates a high degree of inflammation and an insufficient level of hygienic care.

In the third trimester of pregnancy, and immediately in the prenatal period, the process intensified even more: the clinical picture of hypertrophic gingivitis in pregnant women in the control group acquired its maximum development. In $15.63 \%$ (5/32) of women, significant gum growth and the formation of false gingival pockets with serous-hemorrhagic exudate with single necrotization of the tops of hypertrophied papillae were objectively observed. The values of PBI were $1.82 \pm 0.13(\mathrm{p}<0.001)$, which corresponds to the moderate degree of gingivitis.

The highest values of Svrakov's iodine number (5.36 \pm 0.22 scores $)$ and PMA index $(51.42 \pm 1.86 \%)$ were revealed in the third trimester of gestation, which indicates the predominance of inflammatory processes in periodontal tissues during this period. The development of the inflammatory process can be explained by the neglect of women to brush the teeth due to soreness and bleeding of the gums, due to which oral hygiene deteriorates. This is confirmed by the high values of OHI-S (2.46 \pm 0.13 scores), which objectively indicates an insufficient level of hygienic care and an unsatisfactory condition of the oral cavity in women in the control group.

The effectiveness of treatment in the main group was $84.38 \%(27 / 32)$, in the control $-46.88 \%(15 / 32)$. The obtained results of the study indicate that the proposed complex of therapeutic and prophylactic measures in the treatment of inflammatory periodontal diseases in pregnant women with therapeutic efficacy exceeds the generally accepted basic treatment.

\section{DISCUSSION}

At the start of the treatment, the presence of inflammation in the marginal periodontium led to the appearance of false gingival pockets between the gums, which were hypertrophied or enlarged due to exudation, and the tooth surface. After professional oral hygiene and an optimized set of individual measures in both research groups immediately after treatment, a significant decrease $(\mathrm{p}<0.001)$ in the values of OHI-S and PBI was established. However, in the II-III trimesters of pregnancy, the level of hygiene in the control group of the examined is increased again. The dynamics of the indices characterizing the periodontium condition also differed between the research groups. Thus, we noted a 2.7-fold decrease in the PMA index values to $14.80 \pm 1.17 \%(\mathrm{p}<0.001)$ in the main group of pregnant women. At the same time, in one third of women in the control group, according to the PMA index, the prevalence of gingivitis of high intensity $(51.42 \pm 1.86 \%, \mathrm{p}<0.001)$ was established.

The obtained results of a clinical study indicate a pronounced anti-inflammatory effect of a hyaluronic-containing drug, due to the effect on the metabolism of non-sulfated glycosaminoglycans, it provides a reduction in the time for the complete elimination of the inflammatory process, promotes rapid tissue regeneration and, consequently, stops the further progression of the pathological process. In clinical and experimental studies of other authors, it was noted that biotechnologically developed hyaluronic medicines have high bioavailability and $\mathrm{pH}$ level of saliva, anti-inflammatory effects, reduce the level of tissue hypoxia with normalization of energy metabolism, restore the natural viscosity of the connective tissue structure and enhance its protective functions $[1,10,11]$.

In the third trimester of pregnancy and directly in the prenatal period in $84.38 \%(27 / 32)$ of pregnant women of the main group the obtained result was preserved, while in the control group in $53.13 \%$ (17/32) of women relapses of the inflammatory process in the gums were revealed which required repeated treatment, of which $15.63 \%(5 / 32)$ had 
significant gingival growth and the formation of deep gingival pockets with serous-hemorrhagic exudate and single necrotization of tops of hypertrophied papillae.

The successful treatment of gingivitis in the main group of pregnant women can be explained by the prescribing of the probiotic L. reuteri Prodentis, which ensures the restore of the colonization resistance state of the oral biofilm and prevents the occurrence of recurrence of periodontal diseases. The results of our observations correlate with the studies of other authors, which indicate that in addition to the effect on the oral microbiome by destroying or inhibiting the growth of cariogenic and periodontal bacteria, probiotics contribute to the formation of a biofilm, stimulate and modulate mucosal immunity, increase the activity of anti-inflammatory cytokines and, accordingly, reduce production of proinflammatory cytokines by converting histidine into histamine, which suppresses proinflammatory TNF production $[7,12,13,14]$.

\section{CONCLUSIONS}

The effectiveness of treatment in the main group was $84.4 \%$, in the control $-46.9 \%$. The use of the proposed complex of therapeutic and prophylactic measures in the main group of patients contributed to the elimination of the inflammatory process in the periodontal tissues, stopped the progression of existing diseases, made it possible to prevent the emergence of new nosological forms, improved the state of oral hygiene, which allows to recommend it for treatment of periodontal diseases in pregnant women.

\section{REFERENCES}

1. Boychuk-Tovsta 0.G., Rozhko M.M. Clinical evaluation of 0,2\% hyaluronic acid containing gel "gengigel" in the local treatment of pregnant women with generalized periodontitis on the background of IDA. The Pharma Innovation J. 2017;6(5):79-81.

2. Gadzhula N.G. Pidvyshchennia efektyvnosti profilaktyky stomatolohichnykh zakhvoriuvan u vahitnykh iz zaluchenniam sanitarno-prosvitnytskoi roboty [Improving the Efficiency of Dental Diseases Prevention in Pregnant Women with the Involvement of Sanitary and Educational Work]. Novyny stomatolohii. 2020;4(105):127. (in Ukrainian).

3. Geisinger M.L., Geurs N.C., Bain J.L. et al. Oral health education and therapy reduces gingivitis during pregnancy. J Clin Periodontol. 2014;41(2):141-8. doi: 10.1111/jcpe.12188.

4. González-Jaranay M., Téllez L., Roa-López A. et al. Periodontal status during pregnancy and postpartum. PLoS One. 2017;12(5): e0178234. doi: 10.1371/journal.pone.0178234.

5. Gadzhula N.G., Goray M.A. Suchasni aspekty profilaktyky kariiesu zubiv u zhinok pid chas vahitnosti ta laktatsii. [Modern aspects of dental caries prevention in women during pregnancy and lactation]. Visnyk morfolohii. 2016;1(22):179-82. (in Ukrainian).

6. Soma-Pillay P., Nelson-Piercy C., Tolppanen H., Mebazaa A. Physiological changes in pregnancy. Cardiovasc J Afr. 2016;27(2):89-94. doi:10.5830/ CVJA-2016-021.

7. Kshirsagar J.T., Balamurugan A. Role of sex hormones in periodontium during pregnancy: A review. IJADS. 2018;4(4):168-73.
8. Massoni R.S.S., Aranha A.M.F., Matos F.Z. et al. Correlation of periodontal and microbiological evaluations, with serum levels of estradiol and progesterone, during different trimesters of gestation. Sci Rep. 2019;9(1):11762. doi:10.1038/s41598-019-48288-w.

9. Gadzhula N.G., Shinkaruk-Dykovytska M.M., Cherepakha 0.L. et al. Efficiency of using the diode laser in the treatment of periodontal inflammatory diseases. Wiad Lek. 2020;73(5):841-5. doi: https://doi. org/10.36740/WLek202005101.

10. Gupta S., Kediege S.D., Gupta A., Jain K. Evaluation of Gengigel ${ }^{\oplus}$ Application in the Management of Furcation with Coronally Advanced Flap through Surgical Re-Entry-A Split Mouth Clinical Study. J Clin Diagn Res. 2017;11(1):27-32. doi:10.7860/JCDR/2017/21938.9169.

11. Yashika J. Clinical evaluation of $0.2 \%$ hyaluronic acid containing gel in the treatment of gingivitis. Med J DY Patil Univ. 2013;6(4):416-20. doi:10.4103/0975-2870.118296.

12. Hodovanets 0.I., Moroz A.V., Popesku D.G. Zastosuvannia probiotykiv v stomatolohii [The use of probiotics in dentistry]. Klinichna ta eksperymentalna patolohiia. 2017;1(59):164-7. doi: https://doi. org/10.24061/1727-4338.XVI.1.59.2017.37. (in Ukrainian).

13. Jayaram P., Chatterjee A., Raghunathan V. Probiotics in the treatment of periodontal disease: A systematic review. J Indian Soc Periodontol. 2016;20(5):488-95. doi: 10.4103/0972-124X.207053.

14. Schlagenhauf U., Jakob L., Eigenthaler M. et al. Regular consumption of Lactobacillus reuteri-containing lozenges reduces pregnancy gingivitis: an RCT.J Clin Periodontol. 2016;43(11):948-54. doi: 10.1111/ jcpe.12606.

The work is a fragment of the research project "Modern trends and latest technologies in the diagnosis and treatment of odontopathology, diseases of periodontal tissues and oral mucous membrane", state registration No. 0118 U005471.

\section{ORCID and contributionship:}

Nataliia G. Gadzhula: 0000-0003-0016-2264 B,D, E

Olena L. Cherepakha: 0000-0003-3629-4429 D,F

Olena V. Lezhnova: 0000-0002-1393-3163 ${ }^{A, C}$

\section{Conflict of interest:}

The Authors declare no conflict of interest.

CORRESPONDING AUTHOR
Nataliia G. Gadzhula
National Pirogov Memorial Medical University
56 Pyrohov St., 21018 Vinnytsia, Ukraine
tel: +380977011918
e-mail: gadzhula@vnmu.edu.ua

Received: 23.11.2020

Accepted: 29.03 .2021

A - Work concept and design, B - Data collection and analysis, C - Responsibility for statistical analysis, D-Writing the article, $\mathbf{E}$-Critical review, F- Final approval of the article 